\title{
Trends in the Concomitant Prescribing of Opioids and Benzodiazepines, 2002-2014
}

Catherine S. Hwang, MSPH, ${ }^{1}$ Elizabeth M. Kang, MPH, ${ }^{1}$ Cynthia J. Kornegay, PhD, ${ }^{1}$ Judy A.

Staffa, PhD, ${ }^{1}$ Christopher M. Jones, PharmD, MPH, ${ }^{2}$ Jana K. McAninch, MD, MPH, MS ${ }^{1}$

From the ${ }^{1}$ Office of Surveillance and Epidemiology, Center for Drug Evaluation and Research, U.S. Food and Drug Administration, Silver Spring, Maryland; and ${ }^{2}$ Office of Public Health Strategy and Analysis, Office of the Commissioner, U.S. Food and Drug Administration, Silver Spring, Maryland

Address correspondence to: Jana K. McAninch, MD, MPH, MS, U.S. Food and Drug Administration, 10903 New Hampshire Avenue, Silver Spring MD 20993. E-mail: jana.mcaninch@fda.hhs.gov. 
Introduction: Although many clinical guidelines caution against the combined use of opioids and benzodiazepines, overdose deaths and emergency department visits involving the coingestion of these drugs are increasing.

Methods: In this ecologic time series study, the IMS Health Total Patient Tracker was used to describe nationally projected trends of patients receiving opioids and benzodiazepines in the U.S. outpatient retail setting between January 2002 and December 2014. The IMS Health Data Extract Tool was used to examine trends in the concomitant prescribing of these two medication classes among 177 million individuals receiving opioids during this period. The annual proportion of opioid recipients who were prescribed benzodiazepines concomitantly was calculated and stratified by gender, age, duration of opioid use, immediate-release versus extended-release/longacting opioids, and benzodiazepine molecule. The proportion of patients with concomitancy receiving opioids and benzodiazepines from the same prescriber was also analyzed. Analyses were conducted from April to June 2015.

Results: The nationally projected number of patients receiving opioids and benzodiazepines increased by $8 \%$ and $31 \%$, respectively, from 2002 to 2014 . During this period, the annual proportion of opioid recipients dispensed a benzodiazepine concomitantly increased from $6.8 \%$ to $9.6 \%$, which corresponded to a relative increase of $41 \%$. Approximately half of these patients received both prescriptions from the same prescriber on the same day. Concomitancy was more common in patients receiving opioids for $\geq 90$ days, women, and the elderly.

Conclusions: Concomitant prescribing of opioids and benzodiazepines is increasing and may play a growing role in adverse patient outcomes related to these medications. 


\section{Introduction}

Although opioid analgesics are the main driver of prescription drug overdose and death,${ }^{1-4}$ other prescription drugs are commonly involved in opioid-related morbidity and mortality. ${ }^{3-8}$ Benzodiazepines are the most frequently cited co-intoxicants, ${ }^{6-9}$ contributing to approximately one third of all opioid overdose deaths in the U.S. ${ }^{1,3-5}$ This proportion is increasing, and the growth in opioid-related overdose deaths from 2006 to 2011 was largely driven by deaths involving both classes of drugs. ${ }^{9}$ Co-abuse of opioids and benzodiazepines is common, ${ }^{10-12}$ and emergency department visits and substance abuse treatment admissions involving the combined use of these two drug classes are also on the rise. ${ }^{10,13,14}$ Although benzodiazepines alone rarely cause clinically significant respiratory depression, they can worsen opioid-mediated respiratory depression, ${ }^{15-18}$ and recent epidemiologic studies suggest that, after controlling for other factors, the risk of overdose death increases markedly when opioid recipients are also prescribed benzodiazepines. ${ }^{19-21}$

Clinical guidelines generally caution against co-prescribing opioids with benzodiazepines ${ }^{22-31}$; however, the literature on concomitant prescribing is limited. Studies that have examined this phenomenon indicate that benzodiazepines are commonly prescribed with opioids, ${ }^{5,20,21,32-34}$ particularly in patients with chronic pain, ${ }^{35}$ and that co-use may be increasing in some settings. ${ }^{14,36}$ These studies have a number of limitations, including widely varying definitions of concomitancy, lack of information on recent trends, limited generalizability, and use of survey data that may be vulnerable to selection and recall biases. 
The objective of this study was to describe recent trends and patterns in opioid and benzodiazepine utilization and co-prescribing in the U.S. A better understanding of concomitant prescribing will help inform efforts to reduce adverse outcomes associated with these medications.

\section{Methods}

\section{Data Sources}

This study used the IMS Health Vector One®: Total Patient Tracker (TPT), a widely used source of prescription activity data in the U.S. outpatient retail setting, to examine opioid and benzodiazepine utilization between January 2002 and December 2014. The TPT receives raw prescription dispensing data from approximately 33,200 pharmacies each day, representing about $56 \%$ of all prescriptions dispensed in the U.S., and includes transactions paid for by cash, Medicaid, Medicare, and other commercial insurance plans. IMS uses a proprietary algorithm to derive nationally projected estimates of the number of unique patients dispensed a drug product during a specified time period. The data are de-identified prior to entering the database and are available in aggregate form by year.

The IMS Health Vector One®: Data Extract Tool (DET) was then used to examine trends in the concomitant use of opioids and benzodiazepines between January 2002 and December 2014. The DET represents the underlying raw data from which TPT national projections are derived. Although DET data are not nationally projected, linkages between prescription records and deidentified patient, provider, and pharmacy codes allow for detailed patient-level investigations of 
prescription drug utilization patterns in a very large national sample. Analyses were conducted from April to June 2015.

\section{Nationally Projected Trends}

The TPT database was queried by molecule to extract nationally projected annual counts of unique patients dispensed opioids and benzodiazepines from January 2002 to December 2014. These data were then plotted to examine nationally projected trends. All prescriptions were included, regardless of product form or indication, to provide an overall picture of the opioid and benzodiazepine market in the U.S. outpatient retail setting.

\section{Cohort Derivation for Patient-Level Analyses}

For the patient-level concomitancy analyses, Uniform System of Classification codes and product names were used to identify opioid and benzodiazepine prescriptions dispensed between January 2002 and December 2014 in the DET database. Buprenorphine-naloxone products and opioids not dispensed as tablets, capsules, or transdermal patches were excluded minimize capture of cough syrups and other products not indicated for pain and because certain data fields needed to calculate therapy duration, such as days' supply, may not be reliable. The small number of benzodiazepine prescriptions that were not dispensed as tablets or capsules were also excluded. No benzodiazepine products are currently marketed as transdermal patches.

All patients who had an opioid or benzodiazepine prescription meeting these inclusion criteria were identified. Patients meeting any of the following criteria were then excluded from the analytic cohort: unknown age, unknown gender, prescription refill number $>0$ for Schedule II controlled substances, prescription refill number $>5$ for Schedule III and IV controlled 
substances, days' supply $<1$ or $>90$ days, or dispensed quantity $<1$ or $>1,000$ units. Exclusion criteria were based on Controlled Substance Act regulations and judgment that the records likely reflected data entry errors or bulk purchases, or were otherwise unlikely to represent actual dispensings to individual patients.

\section{Concomitancy Analyses}

To account for multiple consecutive prescriptions, continuous therapy episodes were constructed separately for opioids and benzodiazepines using prescription dispensing dates and days' supply in the DET. Gaps in supply of $\leq 7$ days between prescriptions were considered to be a part of the same episode. Overlaps as a result of prescriptions filled early were added to the end of the following prescription, up to a maximum of 7 days.

Trends in the concomitant use of opioids and benzodiazepines were then examined using these therapy episodes. For the primary analysis, all patients with at least one opioid therapy episode beginning in a given year were identified. Among these patients, those with a benzodiazepine episode that overlapped an opioid episode by at least 7 consecutive days were classified as concomitant users. The number of concomitant users was then divided by the total number of patients with an opioid therapy episode during that year.

Stratified analyses by gender, age, and duration of opioid therapy were also performed. Patients were defined as chronic opioid users if they had at least one continuous opioid therapy episode of at least 90 days during the study period. All other patients were considered non-chronic opioid users. 
Next, the analytic sample was further restricted to patients with one or more episodes of concomitancy. Concomitant episodes were categorized as containing only extended-release/longacting opioid prescriptions, only immediate-release opioid prescriptions, or both. To examine which benzodiazepine molecules were more likely to be co-prescribed with opioids, patients with a concomitant episode containing each of the following molecules were identified: alprazolam, clonazepam, diazepam, lorazepam, and temazepam. Finally, the proportion of concomitant users who received a prescription for both an opioid and benzodiazepine from the same prescriber on the same day was examined.

Several sensitivity analyses were performed. First, the primary concomitancy analysis was repeated using a 15-day gap and overlap definition when constructing therapy episodes. Second, a 1-day overlap between opioid and benzodiazepine episodes was used as an alternative definition for concomitant use. Third, the prescriber analysis was repeated, examining the proportion of patients with a concomitant opioid-benzodiazepine episode who received an opioid and benzodiazepine prescription from the same prescriber within 7 days of each other.

All data analyses were conducted using SAS, version 9.4. The study was exempted from review by the U.S. Food and Drug Administration Research Involving Human Subjects Committee.

\section{Results}

The annual number of unique patients dispensed an opioid increased from 75 million to 83 million between 2002 and 2010, and then slightly decreased to 81 million by 2014 (Figure 1). This corresponded to an overall percentage increase of $8 \%$ during the study period. The number 
of unique patients dispensed a benzodiazepine increased by $31 \%$ over the study period, from 23 million in 2002 to 30 million in 2014 (Figure 1).

The final DET analytic sample consisted of 177 million patients who received one or more opioid prescription from 2002 through 2014, representing 94\% of the original opioid data set after applying exclusions, and 65 million patients who received one or more benzodiazepine prescription, representing $97 \%$ of the original benzodiazepine data set (Table 1). In general, those receiving benzodiazepines were older than those receiving opioids. For both drug classes, women were more likely to receive a prescription, although the gender difference was more pronounced for benzodiazepines. Overall, $8 \%$ of opioid recipients were defined as chronic users.

The proportion of opioid recipients with a concomitant benzodiazepine episode increased steadily, from $7 \%$ in 2002 to $10 \%$ in 2014 (Table 2), representing a relative increase of $41 \%$. The median duration of concomitancy was 21 consecutive days, and $23 \%$ of patients with concomitancy had a cumulative duration of overlap of $>90$ days over the study period.

Women opioid users were more likely to receive concomitant benzodiazepines than men, but concomitant use increased for both genders. The proportion of opioid users with a concomitant benzodiazepine was highest in patients aged > 65 years, but those aged 45-64 years comprised the largest absolute number of concomitant users. Concomitant use was considerably higher among chronic opioid users than non-chronic users. However, non-chronic opioid users represented a larger absolute number of concomitant users in the DET data set: $0.7-1.4$ million per year, as compared with 0.4-1.2 million chronic opioid users with concomitant 
benzodiazepine use. In addition, patients with concomitant opioid-benzodiazepine episodes containing only immediate-release opioids comprised the greatest proportion of concomitant users, even among chronic opioid users. Of note, concomitancy among chronic opioid users began to decrease slightly after 2011 (Table 3 ).

The involvement of individual benzodiazepine molecules in concomitancy episodes was generally proportional to their share of the market. Concomitant episodes most commonly contained a prescription for alprazolam (33\%-39\%), diazepam (17\%-21\%), and lorazepam $(13 \%-19 \%)$, which were also the three benzodiazepine molecules with the greatest prescribing volume.

The prescriber-level analysis showed that approximately half of patients with a concomitant opioid-benzodiazepine episode filled an opioid and benzodiazepine prescription from the same prescriber on the same day. These prescribers most commonly specialized in family (18\%), internal (15\%), and emergency medicine (5\%), with psychiatrists (3\%) and pain specialists $(0.3 \%)$ representing a small percentage of concomitant prescribers (data not shown).

Results of sensitivity analyses using therapy episodes with a 15-day gap and overlap were similar to the primary results, and analyses requiring only a 1-day overlap between opioid and benzodiazepine episodes found slightly higher overall concomitancy estimates (10\%-14\%) but similar trends over the study period. The prescriber analysis allowing a 7-day window between same-prescriber opioid and benzodiazepine dispensings generated a higher proportion of concomitancy episodes involving the same prescriber (Table 3). 


\section{Discussion}

Between 2002 and 2014, the number of patients receiving benzodiazepines in the U.S. was substantial and increased to a greater extent than the number of patients receiving opioids. In addition, the proportion of opioid recipients dispensed benzodiazepines concomitantly increased from $7 \%$ to $10 \%$ during this period, corresponding to a relative percent increase of $41 \%$. Applied to nationally projected prescribing estimates, this translates to an increase of more than 2.5 million opioid users receiving concomitant benzodiazepines in 2014, compared to in 2002. Concomitancy was more common among chronic opioid users, women, and the elderly, although in absolute terms, more concomitancy occurred among non-chronic and middle-aged opioid users. More than half of concomitant users received both prescriptions from the same prescriber, most frequently from family or internal medicine providers. Both the increase in benzodiazepine prescribing and the increase in concomitant prescribing raise concerns, given the heightened risk of overdose associated with co-use, ${ }^{19-21}$ clinical guidelines that caution against co-prescribing these drugs in most situations, ${ }^{22-31}$ the growing involvement of benzodiazepines in opioid-related morbidity and mortality, ${ }^{10}$ and increasing treatment admission rates for co-addiction. ${ }^{11,14}$

The growth in patients receiving benzodiazepine therapy over the past decade is noteworthy, considering earlier studies showing that benzodiazepine prescribing was steady or decreasing before $2001 .{ }^{37,38}$ Because of the relatively strict definition of concomitancy used in this study, the overall estimates are lower than some prior research suggesting that between one-fourth and four-fifths of opioid recipients are also prescribed benzodiazepines. ${ }^{20,21,32}$ Although previous work has examined co-prescribing in specific patient populations, ${ }^{5,20,21,33-35}$ this study expands 
the literature by estimating the prevalence of concomitant opioid-benzodiazepine prescribing and documenting increases in concomitant prescribing using 13 years of data from a large national retail pharmacy dispensing database.

The reason for the increases in benzodiazepine prescribing, both overall and in the setting of opioid use, is not entirely clear but may involve growing prescriber comfort with benzodiazepines or beliefs that other pharmacologic or non-pharmacologic treatments are ineffective for conditions such as insomnia, anxiety, and musculoskeletal pain. ${ }^{39,40}$ Additional factors may include insufficient availability and reimbursement of multidisciplinary and integrative treatments for pain and mental health disorders, as well as limited access to addiction treatment services. Weaning chronic users from one or both drug classes can be extremely challenging, especially without access to such resources. Providers have little clear guidance in managing complex patients with both chronic pain and mental health or substance use disorders, particularly in primary care and medically underserved settings. Unfortunately, these patients may be at the highest risk for adverse outcomes from co-use. ${ }^{41,42}$ The recent decline in concomitancy observed in chronic opioid users in this study is perhaps an encouraging sign that awareness of these risks may be growing, but concomitant prescribing remains high in this population.

Although clinical guidelines primarily address concomitant prescribing of benzodiazepines among chronic opioid users, ${ }^{23,24,26}$ this study found that, because most opioid use is short term, the majority of concomitancy cases occurred in the setting of non-chronic opioid use. Moreover, concomitant use primarily involved immediate-release opioids, even among chronic users. 
Therefore, although various efforts have aimed to reduce adverse outcomes associated with the use of extended-release/long-acting opioids and long-term opioid use for chronic pain, ${ }^{43-45}$ these findings suggest that efforts should also focus on immediate-release opioids and concomitant benzodiazepine prescribing among short-term opioid users.

Women were more likely than men to receive opioids and benzodiazepines, both individually and concomitantly. This finding is consistent with evidence that women seek medical care more frequently than men and have a higher prevalence of both chronic pain and mental health conditions for which these medications are often prescribed. ${ }^{46-51}$ However, men exhibit higher rates of overdose deaths and emergency department visits related to the combined non-medical use of opioids and benzodiazepines, ${ }^{10}$ suggesting that men may be at greater risk of adverse outcomes from co-use, particularly those related to misuse and abuse.

The higher proportion of concomitant use in older patients is also consistent with prior research showing that the percentage of U.S. adults receiving a benzodiazepine prescription increases linearly with age,${ }^{52}$ despite clinical guidelines and consensus statements cautioning against the use of benzodiazepines in older adults whenever possible. ${ }^{28-32}$ The high prevalence of chronic pain ${ }^{53}$ and perceptions that benzodiazepines can be used safely in older patients ${ }^{39}$ may contribute to the high rates of concomitancy in this group. Although rates of both overdose death and emergency department visits related to co-use of opioids and benzodiazepines are lower in seniors than younger adults, ${ }^{10}$ the combined use of these drugs has been associated with a number of other important risks, including falls and fractures. ${ }^{54,55}$ 
Given that alprazolam is the most frequently prescribed benzodiazepine, it is not surprising that it was also most commonly involved in concomitancy. The number of emergency department visits related to the non-medical use of alprazolam doubled between 2005 and $2010,{ }^{56}$ suggesting an increasing role of this drug in the misuse and abuse of prescription drugs.

A majority of concomitancy cases involved a single provider prescribing both drugs within a short time window, suggesting the need for improved prescriber education and support in managing these patients. However, opioids and benzodiazepines were also commonly prescribed concomitantly by different providers, possibly reflecting poorly coordinated care, particularly between primary care and mental health providers. Some of these cases could also represent “doctor shopping," where a patient seeks controlled substances from multiple providers for the purpose of abuse or diversion. ${ }^{57}$ Strategies such as integration of behavioral health and primary care services, drug utilization review, and facilitation of prescription drug monitoring program use should be examined as strategies to reduce concomitant prescribing of these potentially dangerous drug combinations by multiple providers. ${ }^{58-61}$

This study raises questions for further investigation, including the need to better understand the clinical context for opioid-benzodiazepine co-prescribing, including use of other first-line medications for anxiety or sleep disorders, as well as clinical scenarios, doses, or specific drug combinations that may confer a higher risk of overdose. In addition, further work is needed to evaluate strategies to reduce co-prescribing and co-use of these drugs, as prescriber guidelines and education may not be sufficient. Multiple approaches should be explored, such as utilization review and provider alerts, better coordination of primary and behavioral health care, and 
improved access to non-pharmacologic and integrative treatment modalities and substance abuse services.

\section{Limitations}

First, the clinical context and indications for concomitant prescribing could not be determined, and dispensing data could not be linked to clinical outcomes to determine the actual risk associated with co-prescribing these drugs. Second, these data represent dispensed prescriptions rather than actual medication use. Third, formal statistical tests of trend or comparisons across demographic groups were not performed; however, given the extremely large size of the DET sample, such tests would have limited utility. Fourth, some patients may have filled additional opioid or benzodiazepine prescriptions at pharmacies not captured in the database, so concomitant prescribing may have been underestimated; however, the proportion of benzodiazepine prescriptions captured among opioid recipients would be expected to remain relatively stable over time. Unlike an insurance claims-based study utilizing a closed cohort of enrolled patients, this study was unable to restrict the study cohort to patients whose prescription data were continuously captured throughout the study period. However, claims databases with enrollment information are typically limited to the commercially insured population, and the inclusion of both cash and Medicaid transactions in this study greatly improves the generalizability of these findings.

\section{Conclusions}

Despite efforts to improve the safety of prescription opioids, concomitant prescribing with benzodiazepines is increasing and may play a growing role in adverse patient outcomes related to 
these drugs. Further work is needed to reduce the co-use of these drug classes in both acute and chronic settings. 


\section{Acknowledgments}

The authors gratefully acknowledge Esther Zhou for helpful discussion and feedback throughout this project. The authors also thank Rajdeep Gill, Grace Chai, and David Moeny for their assistance in acquiring the data and communicating with the data vendor.

The research presented in this paper is that of the authors and does not reflect the official policy or opinion of the U.S. Food and Drug Administration. Support for this study came from the U.S. Food and Drug Administration. This project was supported, in part, by an appointment to the Research Participation Program at the Center for Drug Evaluation and Research, administered by the Oak Ridge Institute for Science and Education (ORISE) through an interagency agreement between the U.S. Department of Energy and the U.S. Food and Drug Administration. ORISE had no role in the study design, review, or decision to publish.

$\mathrm{CH}, \mathrm{JM}, \mathrm{CJ}, \mathrm{CK}$, and JS developed the research question and designed the study. $\mathrm{CH}$ and EK developed the statistical analysis plan and analyzed the data. All authors participated in reviewing and interpreting the results and contributed substantively to the writing of the manuscript. 


\section{References}

1. Jones CM, Mack KA, Paulozzi LJ. Pharmaceutical overdose deaths, United States, 2010. JAMA. 2013;309(7):657-659. http://dx.doi.org/10.1001/jama.2013.272.

2. Warner M, Chen LH, Makuc DM, Anderson RN, Miniño AM. Drug poisoning deaths in the United States, 1980-2008. NCHS Data Brief. 2011;81:1-8.

3. Chen LH, Hedegaard H, Warner M. Drug-poisoning deaths involving opioid analgesics: United States, 1999-2011. NCHS Data Brief. 2014;166:1-8.

4. Warner M, Chen LH, Makuc DM. Increase in fatal poisonings involving opioid analgesics in the United Sates, 1999-2006. NCHS Data Brief. 2009;22:1-8.

5. Paulozzi LJ, Mack KA, Hockenberry JM. Vital signs: variation among states in prescribing of opioid pain relievers and benzodiazepines - United States, 2012. Morb Mortal Wkly Rep. 2014;63(26):563-568.

6. Wolf BC, Lavezzi WA, Sullivan LM, Flannagan LM. One hundred seventy two deaths involving the use of oxycodone in Palm Beach County. J Forensic Sci. 2005;50(1):192-195. http://dx.doi.org/10.1520/JFS2004194.

7. Cone EJ, Fant RV, Rohay JM, et al. Oxycodone involvement in drug abuse deaths: a DAWN-based classification scheme applied to an oxycodone postmortem database containing over 1000 cases. J Anal Toxicol. 2003;27(2):57-67. http://dx.doi.org/10.1093/jat/27.2.57.

8. Cone EJ, Fant RV, Rohay JM, et al. Oxycodone involvement in drug abuse deaths. II. Evidence for toxic multiple drug-drug interactions. J Anal Toxicol. 2004;28(7):217-225. http://dx.doi.org/10.1093/jat/28.4.217. 
9. Calcaterra S, Glanz J, Binswanger IA. National trends in pharmaceutical opioid related overdose deaths compared to other substance related overdose deaths: 1999-2009. Drug Alcohol Depend. 2013;131(3):263-270. http://dx.doi.org/10.1016/j.drugalcdep.2012.11.018.

10. Jones CM, McAninch J. Nonmedical-use related emergency department visits and drug overdose deaths involving the combination of opioid analgesics and benzodiazepines in the United States, 2004-2011. Am J Prev Med. 2015;49(4):493-501. http://dx.doi.org/10.1016/j.amepre.2015.03.040.

11. Jones JD, Mogali S, Comer SD. Polydrug abuse: a review of opioid and benzodiazepine combination use. Drug Alcohol Depend. 2012;125(1-2):8-18. http://dx.doi.org/10.1016/j.drugalcdep.2012.07.004.

12. Compton WM, Volkow ND. Abuse of prescription drugs and the risk of addiction. Drug Alcohol Depend. 2006;83(Suppl 1):S4-7. http://dx.doi.org/10.1016/j.drugalcdep.2005.10.020.

13. Cai R, Crane E, Poneleit K, Paulozzi L. Emergency department visits involving nonmedical use of selected prescription drugs in the United States, 2004-2008. J Pain Palliat Care Pharmacother. 2010;24(3):293-297. http://dx.doi.org/10.3109/15360288.2010.503730.

14. Substance Abuse and Mental Health Services Administration. The TEDS report: admissions reporting benzodiazepine and narcotic pain reliever abuse at treatment entry. Rockville, MD. December 13, 2012.

15. Jann M, Kennedy WK, Lopez G. Benzodiazepines: a major component in unintentional prescription drug overdoses with opioid analgesics. J Pharm Pract. 2014;27(1):5-16. http://dx.doi.org/10.1177/0897190013515001.

16. White JM, Irving RJ. Mechanisms of fatal opioid overdose. Addiction. 1999;94(7):961-972. http://dx.doi.org/10.1046/j.1360-0443.1999.9479612.x. 
17. Pattinson KT. Opioids and the control of respiration. Br J Anaesth. 2008;100(6):747-758. http://dx.doi.org/10.1093/bja/aen094.

18. Lee SC, Klein-Schwartz W, Doyon S, Welsh C. Comparison of toxicity associated with nonmedical use of benzodiazepines with buprenorphine or methadone. Drug Alcohol Depend. 2014;138:118-123. http://dx.doi.org/10.1016/j.drugalcdep.2014.02.014.

19. Peirce GL, Smith MJ, Abate MA, et al. Doctor and pharmacy shopping for controlled substances. Med Care. 2012;50(6):494-500. http://dx.doi.org/10.1097/MLR.0b013e31824ebd81.

20. Park TW, Saitz R, Ganoczy D, Ilgen MA, Bohnert AS. Benzodiazepine prescribing patterns and deaths from drug overdose among US veterans receiving opioid analgesics: case-cohort study. BMJ. 2015;350:h2698. http://dx.doi.org/10.1136/bmj.h2698.

21. Dasgupta N, Funk MJ, Proescholdbell S, Hirsch A, Ribisl KM, Marshall S. Cohort study of the impact of high-dose opioid analgesics on overdose mortality. Pain Med. 2015. Epub ahead of print. http://dx.doi.org/10.1111/pme.12907.

22. Rolfs RT, Johnson E, Williams NJ, Sundwall DN, Utah Department of H. Utah clinical guidelines on prescribing opioids for treatment of pain. J Pain Palliat Care Pharmacother. 2010;24(3):219-235. http://dx.doi.org/10.3109/15360288.2010.503265.

23. Washington Agency Medical Directors Group. Interagency guideline on opioid dosing for chronic noncancer pain. www.agencymeddirectors.wa.gov/Files/OpioidGdline.pdf. Published 2010. Accessed July 2, 2015.

24. Kahan M, Wilson L, Mailis-Gagnon A, Srivastava A, National Opioid Use Guideline G. Canadian guideline for safe and effective use of opioids for chronic noncancer pain: clinical 
summary for family physicians. Part 2: special populations. Can Fam Physician. 2011;57(11):1269-1276.

25. Paone D, Dowell D, Heller D. Preventing misuse of prescription opioid drugs. City Health Information. 2011;30:23-30.

26. Manchikanti L, Abdi S, Atluri S, et al. American Society of Interventional Pain Physicians (ASIPP) guidelines for responsible opioid prescribing in chronic non-cancer pain: Part 2 guidance. Pain Physician. 2012;15(3 Suppl):S67-S116.

27. American Geriatrics Society 2012 Beers Criteria Update Expert Panel. American Geriatrics Society updated Beers Criteria for potentially inappropriate medication use in older adults. $J$ Am Geriatr Soc. 2012;60(4):616-631.

28. Fick DM, Cooper JW, Wade WE, Waller JL, Maclean JR, Beers MH. Updating the Beers criteria for potentially inappropriate medication use in older adults: results of a U.S. consensus panel of experts. Arch Intern Med. 2003;163(22):2716-2724. http://dx.doi.org/10.1001/archinte.163.22.2716.

29. McLeod PJ, Huang AR, Tamblyn RM, Gayton DC. Defining inappropriate practices in prescribing for elderly people: a national consensus panel. CMAJ. 1997;156(3):385-391.

30. Maletta G, Mattox KM, Dysken M. Guidelines for prescribing psychoactive drugs in the elderly: part 1. Geriatrics. 1991;46(9):40-47.

31. American Psychiatric Association Task Force on Benzodiazepine Dependency. Benzodiazepine Dependence, Toxicity, and Abuse. Arlington, VA: American Psychiatric Publishing; 1990. 
32. Gomes T, Mamdani MM, Dhalla IA, et al. Opioid dose and drug-related mortality in patients with nonmalignant pain. Arch Intern Med. 2011;171(7):686-691. http://dx.doi.org/10.1001/archinternmed.2011.117.

33. Lavin RA, Tao XG, Yuspeh L, Bernacki EJ. Impact of the combined use of benzodiazepines and opioids on workers' compensation claim cost. J Occup Environ Med. 2014;56(9):973978. http://dx.doi.org/10.1097/JOM.0000000000000203.

34. Park TW, Bohnert AS, Austin KL, Saitz R, Pizer SD. Regional variation in benzodiazepine prescribing for patients on opioid agonist therapy. Psychiatr Serv. 2014;65(1):4. http://dx.doi.org/10.1176/appi.ps.201300419.

35. Mellbye A, Svendsen K, Borchgrevink PC, Skurtveit S, Fredheim OM. Concomitant medication among persistent opioid users with chronic non-malignant pain. Acta Anaesthesiol Scand. 2012;56(10):1267-1276. http://dx.doi.org/10.1111/j.13996576.2012.02766.x.

36. Kao MC, Zheng P, Mackey S. Trends in benzodiazepine prescription and co-prescription with opioids in the United States, 2002-2009. Pain Med. 2014;15:488.

37. Pincus HA, Tanielian TL, Marcus SC, et al. Prescribing trends in psychotropic medications: primary care, psychiatry, and other medical specialties. JAMA. 1998;279(7):526-531. http://dx.doi.org/10.1001/jama.279.7.526.

38. Stafford RS, MacDonald EA, Finkelstein SN. National Patterns of Medication Treatment for Depression, 1987 to 2001. Prim Care Companion J Clin Psychiatry. 2001;3(6):232-235. http://dx.doi.org/10.4088/PCC.v03n0611. 
39. Cook JM, Marshall R, Masci C, Coyne JC. Physicians' perspectives on prescribing benzodiazepines for older adults: a qualitative study. J Gen Intern Med. 2007;22(3):303-307. http://dx.doi.org/10.1007/s11606-006-0021-3.

40. Everitt H, McDermott L, Leydon G, Yules H, Baldwin D, Little P. GPs' management strategies for patients with insomnia: a survey and qualitative interview study. $\mathrm{Br} J \mathrm{Gen}$ Pract. 2014;64(619):e112-e119. http://dx.doi.org/10.3399/bjgp14X677176.

41. Dunn KM, Saunders KW, Rutter CM, et al. Opioid prescriptions for chronic pain and overdose: a cohort study. Ann Intern Med. 2010;152(2):85-92. http://dx.doi.org/10.7326/0003-4819-152-2-201001190-00006.

42. Paulozzi LJ, Zhang K, Jones CM, Mack KA. Risk of adverse health outcomes with increasing duration and regularity of opioid therapy. J Am Board Fam Med. 2014;27(3):329338. http://dx.doi.org/10.3122/jabfm.2014.03.130290.

43. Food and Drug Administration. Extended-release (ER) and long-acting (LA) opioid analgesics Risk Evaluation and Mitigation Strategy (REMS). www.fda.gov/downloads/Drugs/DrugSafety/PostmarketDrugSafetyInformationforPatientsan dProviders/UCM311290.pdf. Published December 2014. Accessed June 12, 2015.

44. Trescott CE, Beck RM, Seelig MD, Von Korff MR. Group Health's initiative to avert opioid misuse and overdose among patients with chronic noncancer pain. Health Aff (Millwood). 2011;30(8):1420-1424. http://dx.doi.org/10.1377/hlthaff.2011.0759.

45. U.S. Department of Veterans Affairs. VA initiative shows early promise in reducing use of opioids for chronic pain. www.va.gov/opa/pressrel/pressrelease.cfm?id=2529. Published February 25, 2014. Accessed June 30, 2015. 
46. CDC. Visits to physician offices, hospital outpatient departments, and hospital emergency departments, by age, sex, and race. www.cdc.gov/nchs/data/hus/2012/088.pdf. Published 2012. Accessed June 21, 2015.

47. CDC. Persons with hospital stays in the past year, by selected characteristics: United States, selected years 1997-2012. www.cdc.gov/nchs/data/hus/2012/093.pdf. Published 2012. Accessed June 21, 2015.

48. CDC. Expenses for health care and prescribed medicine, by selected population characteristics: United States, selected years 1987-2010. www.cdc.gov/nchs/data/hus/2014/046.pdf. Published 2014. Accessed June 30, 2015.

49. CDC. Severe headaches or migraine, low back pain, and neck pain among adults aged 18 and over, by selected characteristics: United States, selected years 1997-2013. www.cdc.gov/nchs/data/hus/2012/093.pdf. Published 2012. Accessed June 21, 2015.

50. McLean CP, Asnaani A, Litz BT, Hofmann SG. Gender differences in anxiety disorders: prevalence, course of illness, comorbidity and burden of illness. J Psychiatr Res. 2011;45(8):1027-1235. http://dx.doi.org/10.1016/j.jpsychires.2011.03.006.

51. Kessler RC, McGonagle KA, Zhao S, et al. Lifetime and 12-month prevalence of DSM-III-R psychiatric disorders in the United States. Results from the National Comorbidity Survey. Arch Gen Psychiatry. 1994;51(1):8-19. http://dx.doi.org/10.1001/archpsyc.1994.03950010008002.

52. Olfson M, King M, Schoenbaum M. Benzodiazepine use in the United States. JAMA Psychiatry. 2015;72(2):136-142. http://dx.doi.org/10.1001/jamapsychiatry.2014.1763. 
53. Reuben DB, Alvanzo AA, Ashikaga T, et al. National Institutes of Health Pathways to Prevention Workshop: the role of opioids in the treatment of chronic pain. Ann Intern Med. 2015;162(4):295-300. http://dx.doi.org/10.7326/M14-2775.

54. Reisfield GM, Webster LR. Benzodiazepines in long-term opioid therapy. Pain Med. 2013;14(10):1441-1446. http://dx.doi.org/10.1111/pme.12236.

55. Khong TP, de Vries F, Goldenberg JS, et al. Potential impact of benzodiazepine use on the rate of hip fractures in five large European countries and the United States. Calcif Tissue Int. 2012;91(1):24-31. http://dx.doi.org/10.1007/s00223-012-9603-8.

56. Substance Abuse and Mental Health Services Administration. Emergency department visits involving nonmedical use of the anti-anxiety medication alprazolam. http://archive.samhsa.gov/data/2k14/DAWN153/sr153-alprazolam-2014.pdf. Published May 22, 2014. Accessed June 24, 2015.

57. Sansone RA, Sansone LA. Doctor Shopping: a phenomenon of many themes. Innov Clin Neurosci. 2012;9(11-12):42-46.

58. Worley J. Prescription drug monitoring programs, a response to doctor shopping: purpose, effectiveness, and directions for future research. Issues Ment Health Nurs. 2012;33(5):319328. http://dx.doi.org/10.3109/01612840.2011.654046.

59. Finklea K, Sacco LN, Bagalman E. Prescription drug monitoring programs. Washington, D.C. http://fas.org/sgp/crs/misc/R42593.pdf. Published March 24, 2014. Accessed June 30, 2015.

60. Katz N, Panas L, Kim M, et al. Usefulness of prescription monitoring programs for surveillance - analysis of schedule II opioid prescription data in Massachusetts, 1996-2006. Pharmacoepidemiol Drug Saf. 2010;19(2):115-123. http://dx.doi.org/10.1002/pds.1878. 
61. Rutkow L, Turner L, Lucas E, Hwang C, Alexander GC. Most primary care physicians are aware of prescription drug monitoring programs, but many find the data difficult to access. Health Aff (Millwood). 2015;34(3):484-492. http://dx.doi.org/10.1377/hlthaff.2014.1085. 


\section{List of Figures}

Figure 1. Nationally projected trends in the annual number of unique patients dispensed opioids (A) and benzodiazepines (B) in the U.S., 2002-2014.

A. "Other" includes buprenorphine, butorphanol, dihydrocodeine, fentanyl, hydromorphone, levorphanol, meperidine, methadone, morphine, oxymorphone, pentazocine, propoxyphene, and tapentadol.

B. "Other" includes chlordiazepoxide, clobazam, clorazepate, estrazolam, flurazepam, halazepam, midazolam, oxazepam, quazepam, and triazolam.

Source: IMS Health Vector One®: Total Patient Tracker, 2002-2014 
Table 1. Description of the Analytic Sample, 2002-2014

\begin{tabular}{|c|c|c|}
\hline & Opioids & Benzodiazepines \\
\hline Number of patients & $177,079,757^{\mathrm{a}}$ & $65,276,802^{\mathrm{a}}$ \\
\hline Female $(\%)$ & 56.2 & 63.8 \\
\hline \multicolumn{3}{|l|}{ Age at first prescription $(\%)$} \\
\hline $0-17$ years & 7.8 & 3.5 \\
\hline $18-44$ years & 46.7 & 40.1 \\
\hline $45-64$ years & 30.2 & 35.8 \\
\hline 65 years or older & 15.3 & 20.7 \\
\hline Chronic $(\%)^{\mathrm{b}}$ & 7.7 & 23.1 \\
\hline Non-chronic $(\%)^{\mathrm{b}}$ & 92.3 & 76.9 \\
\hline Number of prescriptions & $1,340,391,725$ & $644,154,311$ \\
\hline \multicolumn{3}{|l|}{ Payer type $(\%)$} \\
\hline Cash & 13.3 & 17.0 \\
\hline Medicaid & 27.8 & 22.5 \\
\hline Other commercial health insurance & 58.9 & 60.5 \\
\hline \multicolumn{3}{|l|}{ Census region $(\%)$} \\
\hline Northeast & 15.4 & 17.8 \\
\hline Midwest & 21.8 & 21.0 \\
\hline South & 39.1 & 40.0 \\
\hline West & 23.7 & 21.2 \\
\hline
\end{tabular}

Source: IMS Health Vector One®: Data Extract Tool, 2002-2014

${ }^{a}$ Patients are not mutually exclusive because a patient could have received both an opioid and benzodiazepine prescription during the study period.

${ }^{b}$ Patients with one or more opioid or benzodiazepine episode $\geq 90$ days during the study period are considered chronic users. All other patients are considered non-chronic users. 
Table 2. Proportion of Opioid Recipients With Concomitant Benzodiazepine Use, ${ }^{\text {a } 2002-2014}$ (N=177 million)

\begin{tabular}{|c|c|c|c|c|c|c|c|c|c|c|c|c|c|}
\hline & $\begin{array}{c}2002 \\
\%{ }^{b}\end{array}$ & $\begin{array}{c}2003 \\
\%\end{array}$ & $\begin{array}{c}2004 \\
\%\end{array}$ & $\begin{array}{c}2005 \\
\%\end{array}$ & $\begin{array}{c}2006 \\
\%\end{array}$ & $\begin{array}{c}2007 \\
\%\end{array}$ & $\begin{array}{c}2008 \\
\%\end{array}$ & $\begin{array}{c}2009 \\
\%\end{array}$ & $\begin{array}{c}2010 \\
\%\end{array}$ & $\begin{array}{c}2011 \\
\%\end{array}$ & $\begin{array}{c}2012 \\
\%\end{array}$ & $\begin{array}{c}2013 \\
\%\end{array}$ & $\begin{array}{c}2014 \\
\%\end{array}$ \\
\hline All opioid recipients & 6.8 & 6.6 & 6.8 & 7.3 & 7.6 & 8.2 & 8.6 & 8.5 & 8.5 & 8.6 & 8.7 & 8.5 & 9.6 \\
\hline \multicolumn{14}{|l|}{ Gender } \\
\hline Male & 5.5 & 5.2 & 5.4 & 5.8 & 6.1 & 6.7 & 7.0 & 6.9 & 7.0 & 7.0 & 7.0 & 6.8 & 7.7 \\
\hline Female & 7.7 & 7.5 & 7.8 & 8.3 & 8.6 & 9.3 & 9.8 & 9.6 & 9.6 & 9.7 & 9.9 & 9.7 & 11.0 \\
\hline \multicolumn{14}{|l|}{ Age } \\
\hline 0-17 years & 0.4 & 0.4 & 0.4 & 0.4 & 0.4 & 0.5 & 0.5 & 0.5 & 0.5 & 0.5 & 0.6 & 0.6 & 0.7 \\
\hline $18-44$ years & 4.5 & 4.4 & 4.5 & 5.0 & 5.4 & 6.0 & 6.4 & 6.1 & 6.2 & 6.2 & 6.1 & 5.5 & 6.4 \\
\hline 45-64 years & 8.8 & 8.4 & 8.7 & 9.2 & 9.6 & 10.3 & 10.8 & 11.2 & 11.0 & 11.2 & 11.4 & 11.2 & 12.3 \\
\hline $65+$ years & 11.1 & 10.5 & 10.6 & 10.7 & 9.9 & 10.3 & 10.6 & 11.0 & 11.0 & 11.2 & 11.3 & 11.2 & 12.0 \\
\hline Chronic users $^{\mathrm{c}}$ & 41.4 & 39.1 & 39.3 & 39.5 & 37.2 & 37.8 & 37.7 & 40.5 & 40.3 & 39.7 & 38.0 & 35.5 & 33.9 \\
\hline Non-chronic users ${ }^{c}$ & 3.6 & 3.5 & 3.5 & 3.6 & 3.7 & 4.1 & 4.3 & 4.1 & 4.2 & 4.3 & 4.4 & 4.4 & 5.4 \\
\hline
\end{tabular}

Source: IMS Health Vector One®: Data Extract Tool, 2002-2014

${ }^{a}$ Patients were considered concomitant users if they had one or more opioid and benzodiazepine episodes that overlapped by 7 or more consecutive days.

${ }^{\mathrm{b}}$ Percent of concomitant patients, out of the total number of opioid recipients during a given calendar year.

${ }^{c}$ Patients with at least one opioid episode greater than or equal to 90 days during the study period were considered chronic opioid users. All other patients were considered non-chronic opioid users. For chronic opioid users, concomitancy proportions were based on opioid episodes greater than or equal to 90 days only. 
Table 3. Characteristics of Opioid and Benzodiazepine Prescriptions Among Patients With Concomitant Use, ${ }^{\mathrm{a}} 2002-2014$ (N=16 million)

\begin{tabular}{|c|c|c|c|c|c|c|c|c|c|c|c|c|c|}
\hline & $\begin{array}{c}2002 \\
\% b\end{array}$ & $\begin{array}{c}2003 \\
\%\end{array}$ & $\begin{array}{c}2004 \\
\%\end{array}$ & $\begin{array}{c}2005 \\
\%\end{array}$ & $\begin{array}{c}2006 \\
\%\end{array}$ & $\begin{array}{c}2007 \\
\%\end{array}$ & $\begin{array}{c}2008 \\
\%\end{array}$ & $\begin{array}{c}2009 \\
\%\end{array}$ & $\begin{array}{c}2010 \\
\%\end{array}$ & $\begin{array}{c}2011 \\
\%\end{array}$ & $\begin{array}{c}2012 \\
\%\end{array}$ & $\begin{array}{c}2013 \\
\%\end{array}$ & $\begin{array}{c}2014 \\
\%\end{array}$ \\
\hline \multicolumn{14}{|c|}{$\begin{array}{l}\text { Chronic opioid users with concomitancy whose } \\
\text { opioid episode included }^{c}\end{array}$} \\
\hline ER/LA opioids only & 4.9 & 4.8 & 4.4 & 4.2 & 4.1 & 3.9 & 3.5 & 3.1 & 2.7 & 2.5 & 2.5 & 3.5 & 7.6 \\
\hline IR opioids only & 60.5 & 63.7 & 64.5 & 65.0 & 64.2 & 65.2 & 66.7 & 65.8 & 68.8 & 71.6 & 73.7 & 72.8 & 71.1 \\
\hline Both & 37.1 & 33.3 & 33.0 & 32.6 & 33.6 & 32.6 & 31.4 & 33.0 & 30.1 & 27.4 & 25.3 & 25.1 & 22.1 \\
\hline \multicolumn{14}{|c|}{$\begin{array}{l}\text { Non-chronic opioid users with concomitancy } \\
\text { whose opioid episode included }{ }^{c}\end{array}$} \\
\hline ER opioids only & 4.1 & 3.7 & 2.9 & 2.8 & 3.2 & 3.3 & 2.9 & 2.6 & 2.2 & 1.9 & 1.8 & 1.8 & 3.2 \\
\hline IR opioids only & 91.5 & 92.4 & 93.6 & 93.8 & 93.2 & 93.0 & 93.8 & 94.0 & 94.7 & 95.0 & 95.3 & 95.6 & 94.2 \\
\hline Both & 6.9 & 6.2 & 5.4 & 5.4 & 5.6 & 5.7 & 5.2 & 5.2 & 4.8 & 4.6 & 4.4 & 4.0 & 4.3 \\
\hline \multicolumn{14}{|c|}{$\begin{array}{l}\text { Percent of patients with concomitant episodes } \\
\text { involving }{ }^{c}\end{array}$} \\
\hline Alprazolam & 33.5 & 33.2 & 33.8 & 34.5 & 36.0 & 37.5 & 37.6 & 38.8 & 39.4 & 39.1 & 37.9 & 38.3 & 36.2 \\
\hline Clonazepam & 13.5 & 13.5 & 14.3 & 14.9 & 15.3 & 15.5 & 16.2 & 17.2 & 16.9 & 17.0 & 17.7 & 18.7 & 18.6 \\
\hline Diazepam & 20.8 & 19.5 & 19.2 & 19.3 & 19.3 & 18.6 & 18.3 & 19.1 & 18.7 & 18.8 & 18.5 & 18.8 & 17.1 \\
\hline Lorazepam & 18.9 & 18.0 & 17.8 & 18.1 & 18.0 & 18.2 & 18.3 & 18.2 & 17.6 & 17.6 & 17.5 & 13.0 & 14.4 \\
\hline Temazepam & 11.2 & 10.4 & 10.5 & 10.1 & 9.7 & 9.3 & 8.8 & 8.9 & 8.2 & 7.9 & 7.6 & 7.8 & 7.3 \\
\hline \multicolumn{14}{|c|}{$\begin{array}{l}\text { Percent of patients with concomitancy who } \\
\text { received an opioid and benzodiazepine } \\
\text { prescription from the same prescriber }\end{array}$} \\
\hline Filled on the same day & 55.3 & 53.2 & 52.8 & 53.6 & 54.3 & 55.0 & 54.4 & 55.0 & 55.0 & 54.6 & 53.0 & 50.0 & 46.2 \\
\hline Filled within 7 days & 68.5 & 66.5 & 66.0 & 66.4 & 67.7 & 67.1 & 66.5 & 66.4 & 66.2 & 65.7 & 64.3 & 61.9 & 59.1 \\
\hline
\end{tabular}

Source: IMS Health Vector One®: Data Extract Tool, 2002-2014

${ }^{a}$ Patients were considered to have concomitant use if they had one or more opioid and benzodiazepine episodes that overlapped by 7 or more consecutive days.

${ }^{\mathrm{b}}$ Percent of patients, out of the total number of concomitant patients during a given calendar year.

${ }^{c}$ Percentages do not sum to $100 \%$ because some patients may have had opioid-benzodiazepine concomitancy episodes in multiple categories.

ER/LA, extended-release/long-acting; IR, immediate-release 


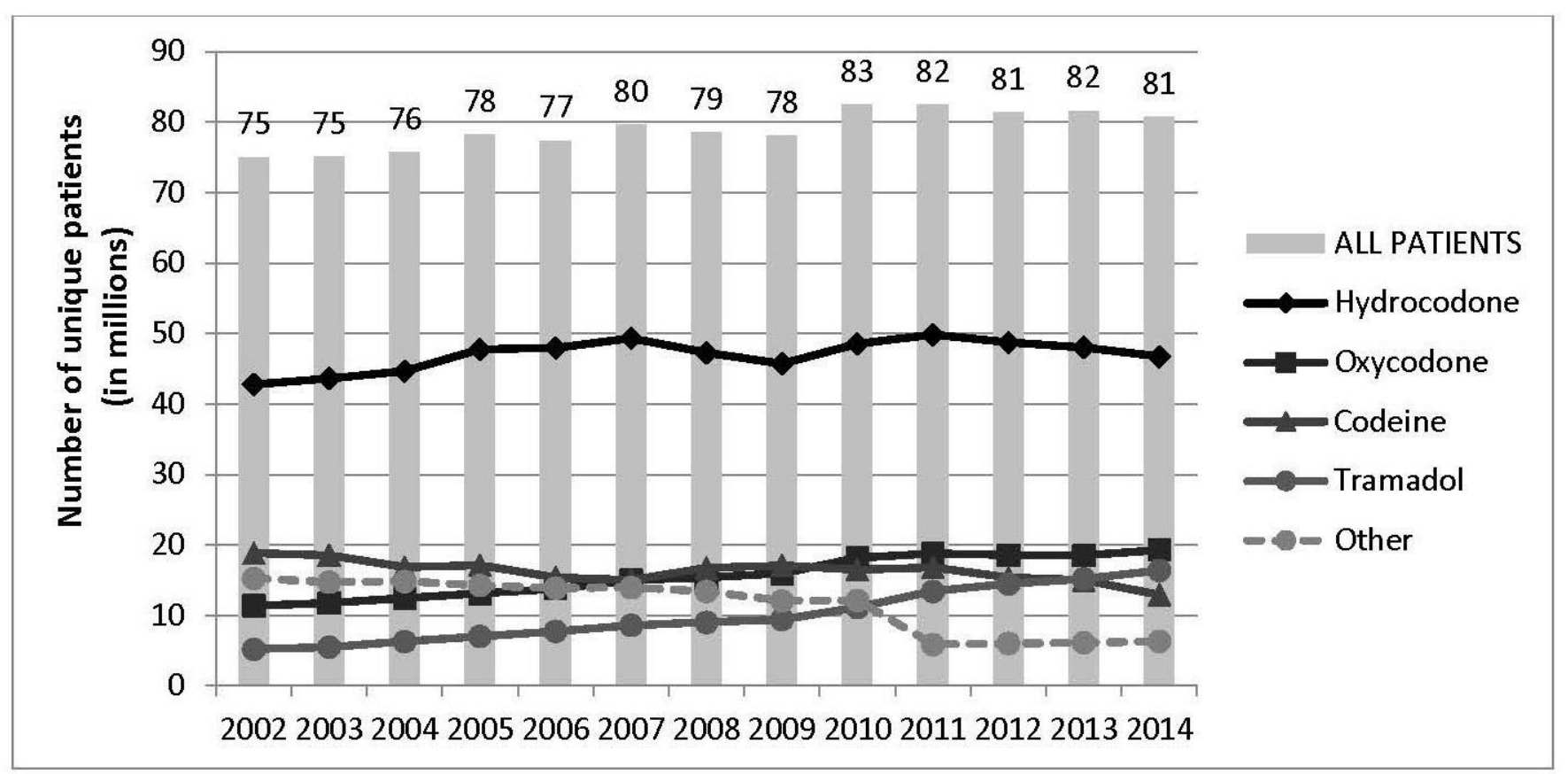




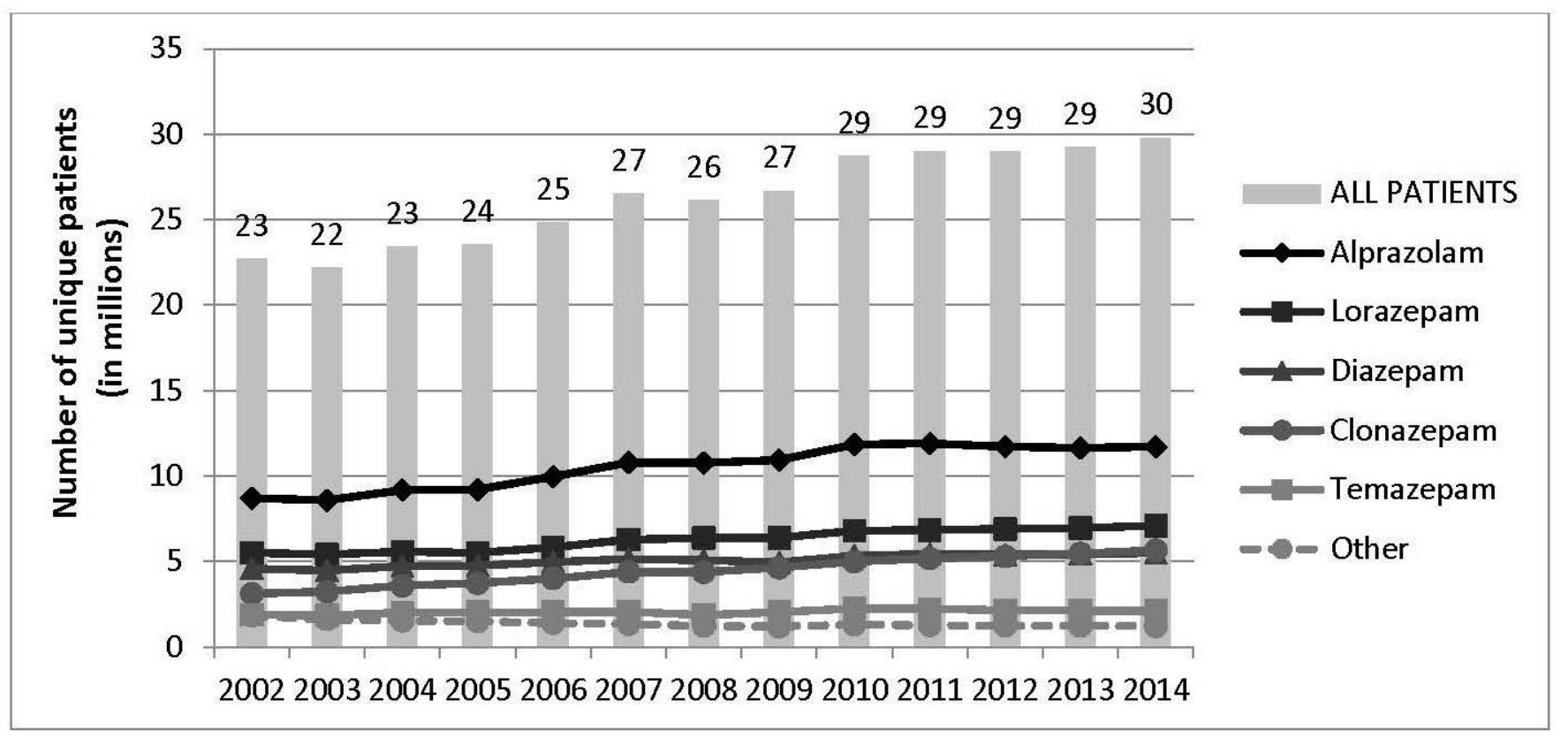

